\title{
IMPLEMENTASI PREVENTIVE MAINTENANCE UNTUK MENINGKATKAN KEANDALAN PADA KOMPONEN KRITIS BOILER DI PEMBANGKIT LISTRIK TENAGA UAP
}

\author{
ling Pamungkas \\ Heri Tri Irawan \\ T.M. Azis Pandria* \\ Program Studi Teknik Industri, Fakultas Teknik, Universitas Teuku Umar
}

\begin{abstract}
This paper uses a preventive maintenance approach in improving the performance reliability of critical boiler components at the Nagan Raya Steam Power Plant (PLTU Nagan Raya). PLTU currently has a strategic role in the electricity system in Indonesia, one of which is PLTU Nagan Raya, located in Aceh. In its implementation, PLTU Nagan Raya often experiences interference in its production system. The boiler is one part that often experiences interference, where corrective maintenance is one of the causes of the interference. Evaluation and performance improvement in terms of reliability is needed to minimize future failures. This research aims to determine the preventive maintenance time based on the reliability value of critical boiler components to increase the reliability value in the future. Preventive maintenance is a preventive activity before a machine breakdown occurs. The reliability value will be calculated in advance before the implementation of preventive maintenance. The implementation of preventive maintenance to increase the reliability of the nine critical components of the boiler obtained maintenance results ranging from 14 days to 47 days with a reliability value of $60 \%$.
\end{abstract}

Keywords:

PLTU; Boiler; Reliability; Preventive Maintenance

\begin{abstract}
Abstrak
Artikel ini menggunakan pendekatan preventive maintenance dalam meningkatkan kinerja keandalan pada komponen kritis boiler di pembangkit listrik tenaga uap (PLTU) Nagan Raya. PLTU saat ini memiliki peran strategis dalam sistem ketenagalistirikan di Indonesia, dan salah satunya yaitu PLTU Nagan Raya yang terdapat di Aceh. Pada pelaksanaannya, PLTU Nagan Raya sering mengalami gangguan pada sistem produksinya. Boiler merupakan salah satu bagian yang sering mengalami gangguan, di mana pemeliharaan korektif menjadi salah satu penyebab terjadinya gangguan. Evaluasi dan peningkatan kinerja dalam hal keandalan diperlukan untuk meminimalkan kegagalan di masa mendatang. Tujuan penelitian ini untuk menentukan waktu perawatan preventif berdasarkan nilai keandalan pada komponen kritis boiler untuk meningkatkan nilai keandalan di masa yang akan datang. Preventive maintenance merupakan kegiatan pencegahan sebelum terjadinya gangguan atau kerusakan pada mesin. Nilai keandalan akan dihitung terlebih dahulu sebelum diterapkannya preventive maintenance. Hasil implementasi preventive maintenance dalam usaha peningkatan keandalan pada sembilan komponen kritis boiler didapatkan hasil pemeliharaan mulai dari 14 hari hingga 47 hari dengan perolehan nilai keandalan $60 \%$.
\end{abstract}

Kata Kunci:

PLTU; Boiler; Keandalan; Preventive Maintenance

DOI: $10.38038 /$ vocatech.v2i2.53

Received: 10 February 2021 ; Accepted: 06 April 2021 ; Published: 20 April 2021

\section{${ }^{*}$ Corresponding author:}

T.M. Azis Pandria, Program Studi Teknik Industri, Fakultas Teknik, Universitas Teuku Umar, Jl. Alue Peunyareng, Meurebo, Aceh Barat, Aceh, 23681.

Email: azispandria@utu.ac.id

Citation in APA Style: Pamungkas, I., Irawan, H.T., \& Pandria, T.M.A., (2021). Implementasi Preventive Maintenance untuk Meningkatkan Keandalan pada Komponen Kritis Boiler di Pembangkit Listrik Tenaga Uap. Vocatech, Vol. 2, 2 (2021), 73-79. 


\section{PENDAHULUAN}

Pembangkit listrik tenaga uap (PLTU) saat ini memiliki peran strategis dalam sistem ketenagalistirikan di Indonesia. Sebagian besar pembangkit listrik di Indonesia menggunakan PLTU karena dianggap lebih ekonomis dan dapat menghasilkan energi listrik yang memadai. Ketersediaan batu bara dengan harga yang terjangkau menjadi faktor utama dalam penggunaan PLTU di Indonesia. Umumnya, pembangkit dan jaringan listrik di Indonesia dikuasai oleh Negara melalui Badan Usaha Milik Negara (BUMN), dan salah satunya yaitu PLTU Nagan Raya yang terdapat di Aceh.

Sistem pemeliharaan atau perawatan yang diterapkan oleh perusahaan pembangkit listrik, akan sangat berpengaruh signifikan terhadap keberlangsungan produksi listrik yang dihasilkan. Sistem produksi suatu perusahaan pada umumnya mempunyai kegiatan perawatan yang baik untuk mendukung kegiatan operasional. Ketika suatu sistem mengalami kerusakan, sistem tersebut memerlukan kegiatan perbaikan. Pembangkit listrik tenaga uap memiliki beberapa bagian utama dalam sistem produksinya seperti boiler, turbin uap, dan generator. Keseluruhan bagian tersebut terintegrasi menjadi satu sistem yang berfungsi untuk menghasilkan listrik.

Pada pelaksanaannya, PLTU Nagan Raya sering mengalami gangguan pada sistem produksinya. Boiler merupakan salah satu bagian yang sering mengalami gangguan, di mana pemeliharaan korektif menjadi salah satu penyebab terjadinya gangguan atau kegagalan. Boiler dikenal sebagai mesin atau alat penghasil uap panas bertekanan tinggi hasil dari pembakaran batubara sebagai sumber panas yang dihasilkan untuk memanaskan air, dan uap panas tersebut kemudian akan digunakan untuk menggerakkan turbin sehingga menghasilkan listrik (Pamungkas, 2019). Boiler memiliki banyak komponen atau peralatan yang apabila pada salah satu komponen atau peralatan tersebut mengalami gangguan atau kegagalan kinerja, maka akan mempengaruhi kinerja secara keseluruhan atau sistem (Pamungkas et al., 2020).

Beberapa studi menunjukkan tingginya frekuensi downtime terjadi karena pemeliharaan tradisional yang diterapkan (Kumar et al., 2017)(Wang et al., 2018). Selain itu, kegagalan juga disebabkan oleh keausan mekanis, umur, daya tahan, elemen material, dan faktor lingkungan (Kurniawan, 2013). Evaluasi kinerja dalam hal keandalan diperlukan untuk meminimalkan gangguan atau kegagalan tersebut. Teori keandalan menentukan kualitas barang yang dapat menentukan kepuasan pelanggan (Kumar et al., 2017). Probabilitas keandalan adalah probabilitas suatu komponen atau sistem untuk beroperasi sesuai dengan fungsi yang diinginkan untuk periode waktu tertentu bila digunakan dalam kondisi operasional tertentu (O'Connor \& Kleyner, 2012).

Upaya untuk meningkatkan keandalan komponen atau mesin, dapat menggunakan beberapa alternatif seperti burning in tasting, derating, replacement parts atau preventive maintenance (Ebeling, 2004). Dalam penelitian ini untuk meningkatkan nilai keandalan akan diterapkan preventive maintenance (perawatan preventif) untuk mendapatkan nilai keandalan minimal enam puluh persen. Perawatan preventif merupakan kegiatan antisipasi yang dilakukan untuk mencegah terjadinya kerusakan yang tidak terduga (O'Connor \& Kleyner, 2012). Beberapa penelitian terdahulu menerapkan perawatan preventif untuk meningkatkan keandalan, seperti menerapkannya pada mesin pompa hidrolik (Febianti \& Ferdinant, 2017), penerapannya pada industri rolling mill (Seiti \& Hafezalkotob, 2019), dan pada penerapan perawatan preventif untuk offshore wind farms (Zhong et al., 2019).

Penelitian ini bertujuan untuk menentukan waktu perawatan preventif berdasarkan nilai keandalan pada komponen kritis boiler untuk meningkatkan nilai keandalan di masa yang akan datang.

\section{STUDI PUSTAKA}

\section{A. Keandalan (reliability)}

Keandalan (reliability) adalah ukuran kemampuan suatu komponen atau peralatan untuk beroperasi terus menerus tanpa adanya gangguan atau kerusakan (Ebeling, 2004). Probabilitas keandalan merupakan probabilitas sebuah komponen atau sistem untuk dapat beroperasi sesuai dengan fungsi yang diinginkan untuk suatu periode waktu tertentu ketika digunakan di bawah kondisi operasional tertentu (O'Connor \& Kleyner, 2012). Keandalan digunakan sebagai salah satu ukuran keberhasilan sistem perawatan serta untuk menentukan jadwal perawatan sebagai langkah pencegahan terjadinya gangguan ataupun kerusakan. Ada empat hal yang signifikan sehubungan dengan pengertian keandalan yaitu (O'Connor \& Kleyner, 2012):

1. Peluang (probability) yaitu setiap komponen memiliki umur atau waktu yang berbeda antara satu dengan yang lain sehingga terdapat sekelompok komponen yang memiliki rata-rata hidup tertentu. 
2. Kinerja keandalan yang diharapkan menjelaskan bahwa keandalan merupakan suatu karakteristik performansi sistem dimana suatu sistem yang handal harus dapat menunjukkan performansi yang memuaskan jika dioperasikan.

3. Waktu merupakan parameter yang penting untuk melakukan penilaian kemungkinan suksesnya suatu sistem. Peluang suatu komponen untuk digunakan selama setahun akan berbeda dengan peluang komponen untuk digunakan dalam sepuluh tahun.

4. Kondisi operasional yang spesifik menjelaskan bahwa bagaimana perlakuan yang diterima oleh suatu sistem dalam menjalankan fungsinya dalam arti bahwa dua buah sistem dengan tingkat mutu yang sama dapat memberikan tingkat keandalan yang berbeda dalam kondisi operasionalnya. Misalnya kondisi temperatur, keadaan atmosfer dan tingkat kebisingan di mana sistem dioperasikan.

\section{B. Perawatan dan Sistem Perawatan}

Perawatan adalah suatu kegiatan untuk memelihara dan menjaga fasilitas yang ada serta memperbaiki, melakukan penyesuaian atau penggantian yang diperlukan untuk mendapatkan suatu kondisi operasi produksi agar sesuai dengan perencanaan yang ada (O'Connor \& Kleyner, 2012; Firnanda \& Ardiansyah, 2020). Ada beberapa tujuan utama dilakukannya perawatan, antara lain (O’Connor \& Kleyner, 2012)

1. Mempertahankan kemampuan alat atau fasilitas produksi.

2. Mengurangi pemakaian dan penyimpangan di luar batas.

3. Menjaga agar kualitas produk berada pada tingkat yang diharapkan.

4. Memperhatikan dan menghindari kegiatankegiatan operasi mesin serta peralatan yang dapat membahayakan keselamatan kerja.

5. Mencapai tingkat biaya serendah mungkin.

6. Mengadakan suatu kerjasama yang erat dengan fungsi-fungsi utama lainnya dari suatu perusahaan

Sistem perawatan dapat dibedakan dalam dua jenis, antara lain:

1. Preventive maintenance adalah kegiatan pemeliharaan dan perawatan yang dilakukan untuk mencegah timbulnya kerusakan-kerusakan yang tidak terduga dan menemukan kondisi yang dapat menyebabkan fasilitas produksi mengalami kerusakan pada waktu proses produksi (Rosa, 2012). Fasilitas produksi yang mendapatkan perawatan akan terjamin kontinuitas kerjanya dan siap dipergunakan untuk proses produksi disetiap saat. Oleh karena itu, dimungkinkan pembuatan suatu jadwal pemeliharaan dan perawatan yang sangat cermat dan rencana produksi yang lebih tepat. Preventive maintenance dapat dibedakan atas dua macam berdasarkan aktivitasnya, yaitu:

a. Perawatan rutin adalah kegiatan pemeliharaan dan perawatan yang dilakukan secara rutin atau dapat dilakukan setiap hari.

b. Perawatan periodik adalah kegiatan perawatan yang dilakukan secara berkala atau dalam jangka waktu tertentu. Contohnya yaitu pengecekan setiap seminggu sekali, sebulan atau setahun sekali.

2. Corrective maintenance merupakan kegiatan perawatan yang dilakukan setelah mesin atau fasilitas produksi mengalami kerusakan atau gangguan sehingga tidak dapat berfungsi dengan baik. Kegiatan ini sering disebut dengan kegiatan perbaikan dan tidak dapat direncanakan terlebih dahulu (Pandi et al., 2017).

\section{METODE}

Objek penelitian yang diamati adalah bagian boiler pada PLTU Nagan Raya. PLTU Nagan Raya terletak di Desa Suak Puntong, Kecamatan Kuala Pesisir, Kabupaten Nagan Raya, Aceh, Indonesia. Data yang dibutuhkan dan kegiatan yang diamati adalah riwayat kerusakan dan kegiatan pemeliharaan yang selama ini dilakukan. Penelitian ini melakukan pengumpulan data melalui observasi langsung dan wawancara dengan pihak perusahaan, khususnya pada bagian perawatan atau pemeliharaan boiler. Hasil penelitian ini diharapkan dapat menjadi acuan dalam pelaksanaan pemeliharaan preventif atau pemeliharaan prediktif. Gambar 1 berikut ini akan menampilkan blok diagram penelitian yang menggambarkan garis besar langkah-langkah penelitian ini.

Berdasarkan Gambar 1, identifikasi masalah dilakukan untuk mengetahui masalah atau gangguan yang sering terjadi pada PLTU Nagan Raya. Boiler menjadi salah satu bagian yang sering terjadi gangguan dan diketahui pihak perusahaan masih menggunakan sistem perawatan korektif yang menjadi penyebab seringnya terjadi gangguan. Maka dapat dirumuskan bahwa evaluasi perlu dilakukan yaitu dalam hal peningkatan kinerja keandalan untuk meminimalkan kegagalan khususnya pada bagian boiler di masa mendatang. 


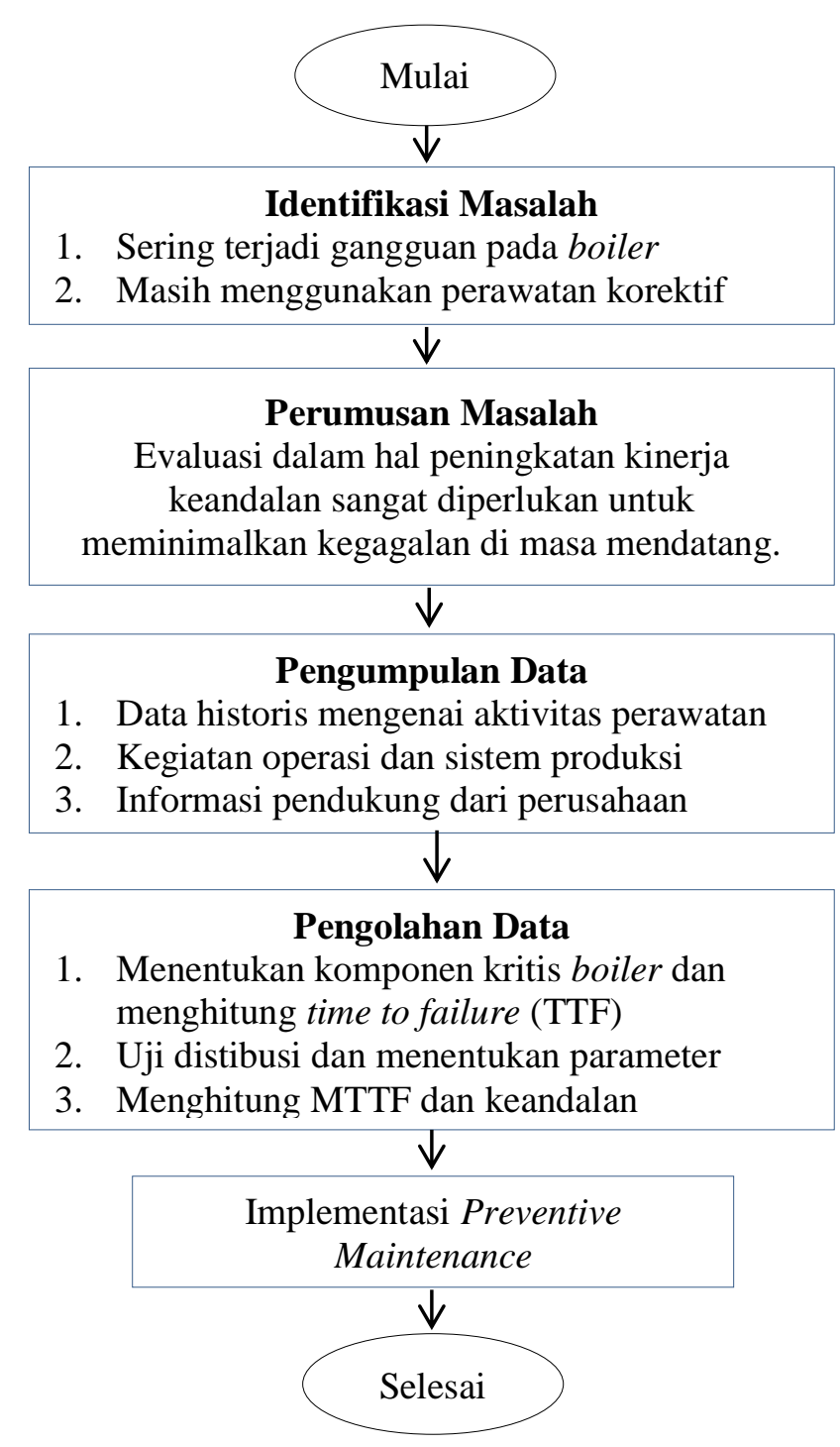

Gambar 1. Blok Diagram Penelitian

Pada tahap pengolahan data, dibutuhkan data waktu antar kerusakan atau time to failure (TTF) pada setiap komponen yang dianggap penting atau dapat disebut komponen kritis pada bagian boiler. Penentuan komponen kritis akan didasarkan pada komponen yang mengalami minimal sepuluh kali kerusakan atau gangguan. Setelah diketahui TTF komponen kritis boiler, langkah selanjutnya adalah menentukan distribusi dan parameter yang akan digunakan untuk menghitung nilai keandalan. Dugaan distribusi yang digunakan yaitu distribusi normal, lognormal, $2 \mathrm{p}$ dan $3 \mathrm{p}$ weibull, dan eksponensial (Jardine \& Tsang, 2013). Langkah terakhir adalah menerapkan sistem preventive maintenance, di mana perawatan akan dilakukan sebelum terjadinya gangguan atau kerusakan. Preventive maintenance akan diterapkan hingga nilai keandalan mencapai enam puluh persen, di mana hal ini dilakukan agar perawatan tidak sering dilakukan karena akan berpengaruh terhadap biaya perawatan. Pencapaian nilai keandalan enam puluh persen akan dilakukan melalui pendekatan simulasi harian perawatan hingga nilai keandalan yang diinginkan tercapai.

\section{HASIL DAN PEMBAHASAN}

\section{A. Spesifikasi Boiler}

Boiler PLTU Nagan Raya menggunakan boiler circulating fluidizing bed (CFB). Adapun secara sistem dapat dilihat pada Gambar 2 berikut ini.

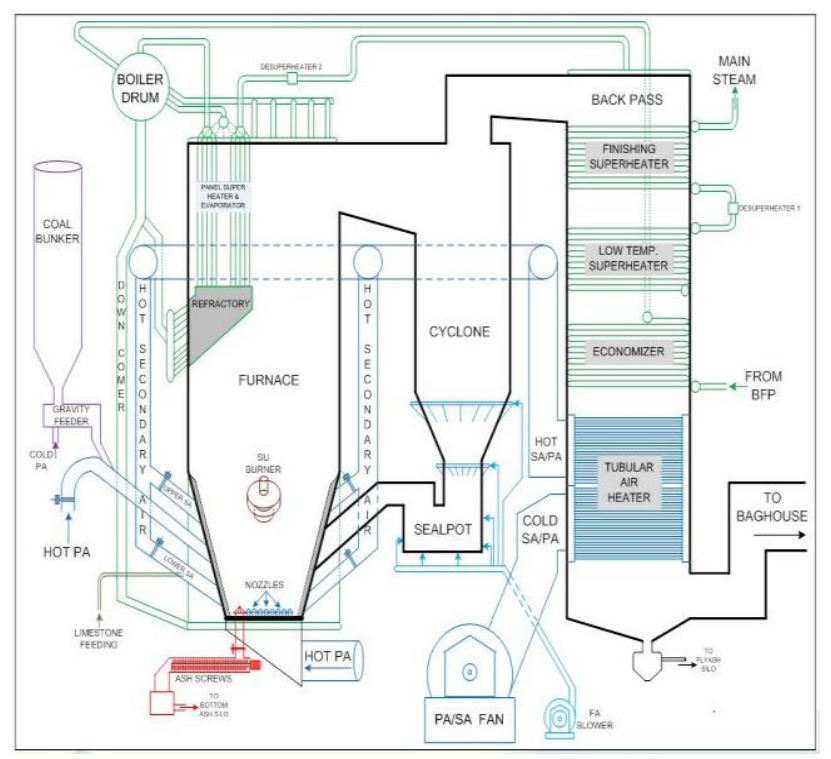

\section{Gambar 2. Boiler di PLTU Nagan Raya Secara Sistem}

PLTU Nagan Raya 2x110 megawatt menggunakan boiler merek Wuxi Huaguan Boiler Co, Ltd, dengan spesifikasi teknis sebagai berikut.

$\begin{array}{ll}\text { Model } & : \mathrm{UG}-430 / 9.8-\mathrm{M} \\ \text { Steam Temperature } & : 540^{\circ} \mathrm{C} \\ \text { Steam Pressure } & : 9.8 \mathrm{MPa} \\ \text { Product Number } & : 09046 \\ \text { Manufacturing License }: \text { TS2110520-2010 }\end{array}$

\section{B. Menentukan Komponen Kritis Boiler}

Komponen kritis boiler akan ditentukan berdasarkan komponen yang memiliki setidaknya sepuluh kegagalan. Daftar nama komponen dan frekuensi kegagalan yang terjadi pada periode Juni 2013 hingga Agustus 2015 pada Gambar 3. 


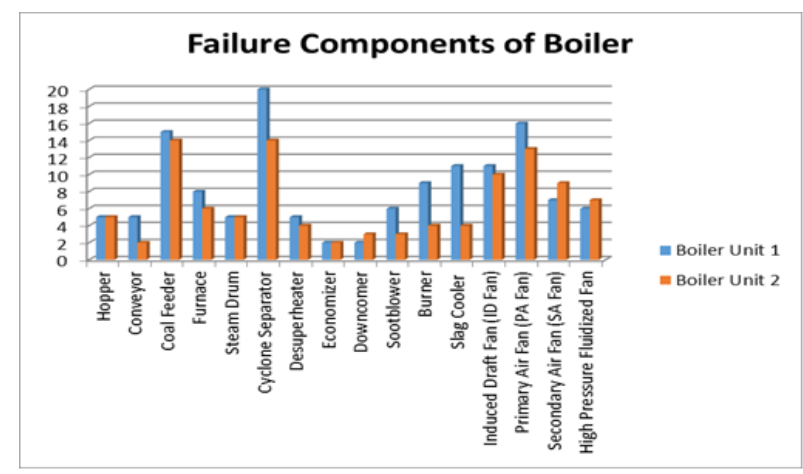

Gambar 3. Frekuensi Kegagalan pada Komponen Boiler Unit 1 dan 2

Berdasarkan Gambar 3, yang termasuk komponen kritis melalui acuan frekuensi 10 kegagalan, maka komponen kritis pada boiler unit 1 yaitu komponen cyclone separator, coal feeder, ID fan, PA fan dan slag cooler. Sedangkan komponen kritis pada boiler unit 2 yaitu komponen cyclone separator, coal feeder, fan ID dan PA fan. Keseluruhan komponen kritis ini kemudian akan ditentukan distribusi dan nilai parameter untuk setiap komponen.

\section{Uji Distribusi dan Menghitung Parameter untuk Time to Failure (TTF)}

Uji distribusi dilakukan pada time to failure (TTF). Jenis distribusi yang digunakan adalah distribusi normal, lognormal, $2 p$ dan $3 p$ weibull, dan eksponensial (Jardine \& Tsang, 2013). Penentuan distribusi terpilih akan menggunakan dua teknik penilaian, Anderson Darling (AD) dan Pearson koefisien korelasi (Pamungkas \& Irawan, 2020). Nilai Anderson Darling menggunakan pendekatan jarak kuadrat tertimbang, dimana nilainya ditentukan oleh nilai terkecil dari Anderson Darling. Sedangkan nilai koefisien korelasi Pearson menggunakan pendekatan estimasi kuadrat terkecil, dimana nilai tersebut ditentukan oleh nilai koefisien korelasi terbesar. Kemudian, parameter ditentukan berdasarkan distribusi yang dipilih sebelumnya (Soesetyo \& Bendatu, 2014). Tabel 1 dan 2 berikut ini menampilkan rekapitulasi distribusi dan parameter terpilih untuk TTF.

Tabel 1. Rekapitulasi Distribusi Terpilih untuk Time to Failure (TTF)

\begin{tabular}{|c|c|c|}
\hline Boiler & Komponen & Distribusi \\
\hline \multirow{5}{*}{$\begin{array}{c}\text { Unit } \\
1\end{array}$} & Cyclone Separator & 2P-Weibull \\
\hline & Coal Feeder & 3P-Weibull \\
\hline & ID Fan & 3P-Weibull \\
\hline & PA Fan & 3P-Weibull \\
\hline & Slag Cooler & 3P-Weibull \\
\hline Unit & Cyclone Separator & Normal \\
\hline 2 & Coal Feeder & 3P-Weibull \\
\hline
\end{tabular}

$\begin{array}{ll}\text { ID Fan } & \text { 3P-Weibull } \\ \text { PA Fan } & \text { 3P-Weibull }\end{array}$

Tabel 2. Rekapitulasi Parameter dari Distribusi

Terpilih untuk Time to Failure (TTF)

\begin{tabular}{|c|c|c|c|c|}
\hline \multirow{3}{*}{ Boiler } & \multirow{3}{*}{ Komponen } & \multicolumn{3}{|c|}{ Parameter } \\
\hline & & \multicolumn{3}{|c|}{ Weibull } \\
\hline & & $\theta$ & $\beta$ & $\Gamma$ \\
\hline \multirow{5}{*}{$\begin{array}{c}\text { Unit } \\
1\end{array}$} & $\begin{array}{l}\text { Cyclone } \\
\text { Separator }\end{array}$ & 45,3291 & 1,60229 & - \\
\hline & Coal Feeder & 41,5813 & 0,75295 & 10,7927 \\
\hline & ID Fan & 36,1957 & 0,74912 & 12,0363 \\
\hline & PA Fan & 24,9251 & 0,89009 & 19,2769 \\
\hline & Slag Cooler & 43,7578 & 0,58997 & 9,5246 \\
\hline \multirow{6}{*}{$\begin{array}{c}\text { Unit } \\
2\end{array}$} & Coal Feeder & 24,7725 & 0,73746 & 6,1975 \\
\hline & ID Fan & 78,7161 & 1,36049 & 7,5417 \\
\hline & PA Fan & 46,0149 & 0,74675 & 13,1217 \\
\hline & & \multicolumn{3}{|c|}{ Normal } \\
\hline & & $\mu$ & & $\Sigma$ \\
\hline & $\begin{array}{l}\text { Cyclone } \\
\text { Separator }\end{array}$ & 56,384 & & 6,5654 \\
\hline
\end{tabular}

\section{Menghitung Mean Time to Failure (MTTF) dan Keandalan}

Setelah parameter dari masing-masing komponen kritis boiler diketahui, langkah selanjutnya adalah menghitung mean time to failure (MTTF) dan keandalan. Perhitungan MTTF dan keandalan komponen cyclone separator pada boiler unit 1 melalui persamaan 1 dan 2 berikut ini (Ebeling, 2004).

$$
\begin{aligned}
\text { MTTF } & =\gamma+\theta \cdot \Gamma\left(1+\frac{1}{\beta}\right) \\
& =0+45,3291 \times \Gamma\left(1+\frac{1}{1,60229}\right) \\
& =0+45,3291 \times \Gamma(1,62) \\
& =0+45,3291 \times 0,89592 \\
& =40,61=40 \text { hari } \\
R(t)= & e^{-\left(\frac{t-\gamma}{\theta}\right)^{\beta}} \\
= & \exp \left[-\left(\frac{40,61-0}{45,3291}\right)^{1,60229}\right]=0,2380=23,80 \%
\end{aligned}
$$

Hasil perhitungan komponen cyclone separator boiler unit 1 diperoleh interval perawatan 40 hari dengan keandalan 23,80\%. Tabel 3 menunjukkan rekapitulasi MTTF dan keandalan masing-masing komponen kritis boiler. 
Tabel 3. Rekapitulasi MTTF dan Keandalan

\begin{tabular}{llcc}
\hline Boiler & \multicolumn{1}{c}{ Komponen } & $\begin{array}{c}\text { MTTF } \\
\text { (Hari) }\end{array}$ & Keandalan \\
\hline \multirow{4}{*}{ Unit 1 } & Coclone Separator & 40 & $23,80 \%$ \\
& ID Fan & 60 & $40,87 \%$ \\
& PA Fan & 55 & $41,06 \%$ \\
& Slag Cooler & 45 & $39,05 \%$ \\
\hline \multirow{4}{*}{ Unit 2 2 Colone Separator } & 77 & $40,20 \%$ \\
& Coal Feeder & 36 & $50,00 \%$ \\
& ID Fan & 79 & $40,95 \%$ \\
& PA Fan & 68 & $40,73 \%$ \\
& & & \\
\hline
\end{tabular}

Berdasarkan Tabel 3, dapat diartikan bahwa diperlukan waktu pemeliharaan diperlukan setiap antara 36 hari hingga 79 hari dengan nilai keandalan $23 \%$ hingga $50 \%$. Nilai keandalan ini termasuk rendah karena tidak mencerminkan sistem perawatan yang baik.

\section{E. Implementasi Preventive Maintenance}

Strategi yang digunakan untuk meningkatkan nilai keandalan adalah dengan melaksanakan kegiatan preventive maintenance (perawatan preventif). Perawatan preventif adalah tindakan pencegahan sebelum terjadi kerusakan. Upaya peningkatan kehandalan komponen atau mesin dengan weibull terdistribusi dapat digunakan Burn-in Testing, dengan parameter nilai $\beta<1$ (menurunkan tingkat kegagalan), tetapi jika $1<\beta<2$ atau $\beta>2$ (meningkatkan tingkat kegagalan), maka beberapa alternatif dapat digunakan Penurunan, Penggantian Part atau Perawatan Preventif (Ebeling, 2004).

Nilai keandalan yang akan ditingkatkan dari masing-masing komponen kritis boiler adalah enam puluh persen $(60 \%)$ dari kondisi sebelum dilakukan pemeliharaan preventif. Target $60 \%$ ditetapkan karena mempertimbangkan aspek intensitas perawatan, dimana semakin tinggi nilai keandalan, maka semakin sering pula dilakukan perawatan, dan akan berpengaruh pula ke biaya perawatan yang semakin tinggi. Untuk memperoleh nilai keandalan $60 \%$ tersebut, maka akan digunakan pendekatan simulasi hingga diperoleh nilai keandalan yang diinginkan. Tabel 4 berikut ini akan menampilkan simulasi interval perawatan dan nilai keandalan komponen cyclone separator boiler unit 1.

Tabel 4. Simulasi Interval Perawatan dan Nilai Keandalan Komponen Cyclone Separator pada Boiler Unit 1.

\begin{tabular}{rcc}
\hline $\mathrm{t}$ (day) & $\mathrm{F}(\mathrm{t})$ & $\mathrm{R}(\mathrm{t})$ \\
\hline 80 & 0,9409 & 0,0591 \\
70 & 0,9158 & 0,0842 \\
60 & 0,8801 & 0,1199
\end{tabular}

\begin{tabular}{rrr}
50 & 0,8292 & 0,1708 \\
40 & 0,7568 & 0,2432 \\
30 & 0,6537 & 0,3463 \\
20 & 0,5069 & 0,4931 \\
14 & 0,3904 & 0,6096 \\
10 & 0,2978 & 0,7022 \\
5 & 0,1620 & 0,8380 \\
1 & 0,0347 & 0,9653 \\
\hline
\end{tabular}

Berdasarkan hasil simulasi interval perawatan, dengan demikian usulan untuk nilai keandalan komponen cyclone separator pada boiler unit 1 adalah dapat dilakukan pemeliharaan preventif setiap 14 hari sekali untuk mencapai nilai keandalan sebesar $60.96 \%$. Tabel 5 beikut ini akan menampilkan rekapitulasi waktu pemeliharaan preventif yang diusulkan untuk meningkatkan keandalan.

Tabel 5. Rekapitulasi Usulan Waktu Perawatan Preventif Pada Komponen Kritis Boiler

\begin{tabular}{clcc}
\hline \multirow{2}{*}{ Boiler } & \multicolumn{1}{c}{ Komponen } & $\begin{array}{c}\text { MTTF } \\
\text { (Hari) }\end{array}$ & Keandalan \\
\hline \multirow{4}{*}{ Unit } & Cyclone Separator & 14 & $60,96 \%$ \\
1 & Coal Feeder & 39 & $60,00 \%$ \\
& ID Fan & 36 & $60,90 \%$ \\
& PA Fan & 33 & $61,26 \%$ \\
& Slag Cooler & 47 & $60,33 \%$ \\
\hline \multirow{4}{*}{ Unit } & Cyclone Separator & 47 & $60,13 \%$ \\
2 & Coal Feeder & 23 & $60,64 \%$ \\
& ID Fan & 37 & $60,10 \%$ \\
& PA Fan & 44 & $60,59 \%$ \\
\hline \multirow{2}{*}{}
\end{tabular}

\section{KESIMPULAN}

Hasil perawatan preventif (preventive maintenace) yang diusulkan untuk sembilan komponen kritis pada boiler untuk mendapatkan nilai keandalan 60\%, diperoleh interval hari perawatan terpendek yaitu 14 hari dan interval hari perawatan terpanjang yaitu 47 hari. Semakin tingginya intensitas perawatan yang dilakukan atau interval hari perawatan yang pendek, dapat memperpanjang umur komponen pada boiler sehingga biaya yang dikeluarkan pun akan minim atau optimal.

\section{REFERENSI}

Ebeling, C. E. (2004). An Introduction to Reliability and Maintainability Engineering. Tata McGraw-Hill Education.

Febianti, E., \& Ferdinant, P. F. (2017). Peningkatkan

VOCATECH: Vocational Education and Technology Journal 2, 2 (2021): 73-79 
Keandalan Mesin Main Pump Hydraulic Unit pada Lini Continuous Casting (Studi Kasus: PT. XYZ). Jurnal Teknik Industri Untirta.

Firnanda, A., \& Ardiansyah, H. (2020). Analisis

Kebutuhan Daya Listrik di Akademi Komunitas Negeri Aceh Barat. VOCATECH: Vocational Education and Technology Journal, 2(1), 59-66.

Jardine, A. K. S., \& Tsang, A. H. C. (2013). Maintenance, Replacement, and Reliability: Theory and Applications. CRC Press.

Kumar, S., Raj, B., \& Shubham, S. (2017). Study of Total Productive Maintenance \& It's Implementation Approach in Steel Manufacturing Industry: A Case Study of Equipment Wise Breakdown Analysis. International Research Journal of Engineering and Technology (IRJET), 4(8), 608-613.

Kurniawan, F. (2013). Teknik dan Aplikasi Manajemen Perawatan Industri. Graha Ilmu: Yogyakarta.

O'Connor, P., \& Kleyner, A. (2012). Practical Reliability Engineering. John Wiley \& Sons.

Pamungkas, I, Irawan, H. T., \& Saputra, A. (2020). Risk and Reliability Analysis on Critical Components of Boiler in Steam Power Plant. IOP Conference Series: Materials Science and Engineering, 1003(1), 12048. IOP Publishing.

Pamungkas, ling. (2019). Penentuan Tingkat Risiko dan Keandalan pada Boiler di Industri Pembangkit Listrik Nagan Raya. ETD Unsyiah.

Pamungkas, Iing, \& Irawan, H. T. (2020). Strategi Pengurangan Risiko Kerusakan pada Komponen Kritis Boiler di Industri Pembangkit Listrik. Jurnal Optimalisasi, 6(1), 86-95.

Pandi, S. D., Santosa, H., \& Mulyono, J. (2017). Perancangan Preventive Maintenance pada Mesin Corrugating dan Mesin Flexo di PT. Surindo Teguh Gemilang. Widya Teknik, 13(1), 33-38.

Rosa, Y. (2012). Perencanaan dan Penerapan Preventive Maintenance Peralatan Laboratorium. Jurnal Teknik Mesin, 2(2), 106119.

Seiti, H., \& Hafezalkotob, A. (2019). Developing the R-TOPSIS Methodology for Risk-Based Preventive Maintenance Planning: A Case Study in Rolling Mill Company. Computers \& Industrial Engineering, 128, 622-636.

Soesetyo, I., \& Bendatu, L. Y. (2014). Penjadwalan Predictive Maintenance dan Biaya Perawatan Mesin Pellet di PT Charoen Pokphand Indonesia-Sepanjang. Jurnal Titra, 2(2), 147154.

Wang, Z., Xiao, C., Lin, X., \& Lu, Y.-Y. (2018). Single Machine Total Absolute Differences Penalties Minimization Scheduling with A
Deteriorating and Resource-Dependent Maintenance Activity. The Computer Journal, 61(1), 105-110.

Zhong, S., Pantelous, A. A., Goh, M., \& Zhou, J. (2019). A Reliability-and-Cost-Based Fuzzy Approach to Optimize Preventive Maintenance Scheduling for Offshore Wind Farms. Mechanical Systems and Signal Processing, 124, 643-663. 